\title{
Review on the Sensor Technology Applied in the Intelligent Learning Environment
}

\author{
Jinhua Chen ${ }^{1}$, Ying $\mathrm{Li}^{2}$, Jing Song ${ }^{3}$ \\ ${ }^{1}$ School of Computer and Information Engineering, Yibin University, Yibin, PRC \\ ${ }^{2}$ School of computer \& information science, Southwest University, Chongqin, PRC \\ ${ }^{3}$ School of information science \& technology, Southwest Jiaotong University, Chengdu, PRC \\ Email: jxxcjh@126.com, lywjl@swu.edu.cn, happygirljing2008@163.com
}

Received 2012

\begin{abstract}
The development of sensor technology promotes the transformation of the intelligent learning environment. Through the research of the sensor technology application, this paper described the intelligent learning environment application system of the sensor technology and the management functions, conference organization, a library building, information collection, monitoring and equipment sharing function the role of sensor technology played in the intelligent learning environment.
\end{abstract}

Keywords: Sensor; The Intelligent Learning Environment; Application; Review

The sensor technology is one of the rapid development high technology of the world. If we take the computer as the extension of the human brain, then the sensor is the extension of human facial features.[1]The sensor technology is the important technical support of the intelligent learning environment construction, the paper comments on the sensor technology applied in the intelligent learning environment.

\section{Overview of Related Concepts}

\subsection{Sensor Technology}

The sensor is the device or devices that can extract and perceive information, and convert it into usable output signal in accordance with certain rules. With the rapid development of science and technology, today's intelligent sensor has the automatic data acquisition, storage, memory and information processing functions.[2]Such as the combination of light and color sensors, infrared sensors, ambient light sensor and LED can improve the comfort feeling of class participation.[3]The picture and sound sensors are real-time collection and testing of learners' facial expressions, voice emotion and attitude and emotional information; The skin current sensor is a real-time measurement of the learners skin conductivity coefficient, to measure the tension of the learner through the changes of conductivity; Pulse pressure sensors monitor learners pulse pressure changes caused by the heart changes; The sweat sensors monitor learners breathing and sweat through its telescopic change; Muscle Current sensor is used to measure the weak voltage values of the learners' muscle movement, in order to obtain the posture emotional information of the learners in interactive learning,[4] providing intelligent learning environment for learners.

\subsection{Intelligent Learning Environment}

We believe that the intelligent learning environment is a learning place or activity space which can perceive learning scenarios, identify learner characteristics, provide appropriate learning resources and facilitate the interactive tools, and automatically record the learning process and evaluation of learning outcomes, in order to promote learners for effective learning.[5]Intelligent learning environment should have the following characteristics: 1) The intelligent learning environment is the seamless integration of the virtual environment and physical environment. 2) Intelligent learning environment emphasizes the records of learners' learning process, personality assessment, the effect evaluation and content push. 3) Intelligent learning environment supports both formal learning and informal learning.

\section{Intelligent Learning Environment Application System of the Sensor Technology}

Through the context-aware device such as the embedded computer and multi-modal sensors, the sensors can aware learners' voice, movement, operating practices and per- 
sonal preferences, and according to learners' personality, hobbies, and historical information, the learner can choose topics and partners in the intelligent learning environment, providing intelligent recommendation learning materials for learners. The intelligent learning environment application system consists of the following components:

1) The sensor module: the sensor module aware learner context information and environmental context information, Such as RFID (radio frequency identification) sensors. By analyzing the learner or the surrounding environment, such as location, learner behavior, environmental temperature and humidity, etc, the intelligent learning environment could be better understand the behavior of the learners as well as the change of the real-world environmental parameters, so as to provide learners resources and services to meet the situation.[6]

2) The Micro-processing module: Microprocessor with memory function can be built into any object and equipment. The memory of each microprocessor is related to the attached entity information. When learners contact with these objects or devices, sensors detect their status and transmit relevant information to learners' mobile devices.

3) The information processing module: Used to implement signals analog-digital conversion, signal display, storage and analysis and processing. Including signal sensing subsystem, and signal acquisition, storage and processing subsystem. The signal sensing subsystem is used to convert change signal to analog signals change over time, for filtered and amplified and sent to the signal acquisition, storage, handling and processing subsystem.

4) The intelligent terminal module: Intelligent terminal module with wireless communication technologies and Internet technology information perceive the surrounding environment and interact with devices embedded in the environment so that students could timely access to computing services and collaborative learning.[7]

\section{Application of the Sensor Technology to Intelligent Learning Environment}

\subsection{Sensor Technology Used In Learner Management of Wisdom Learning Environment}

Sensor technology is used in learner management of intelligent learning environment. It is important to use sensors integrating smart card, each learner with a smart card, used in the intelligent of the learning environment in and out management, dormitory management, learning attendance, meeting attendance, etc.[8]

1) In and out management. The distance induction of antenna of sensor technology can realize contactless automatic check registration; the system can read and manage smart card information automatically.

2) Accommodation management. As learners, carrying the sensor technology card, passed the accommodation entrances, it can contact less sense the turnover of learners, statistic the number of accommodation and give SMS tip, solve the problem of overindulging. At the same time, it can send information to the manager to realize network visual management.

3) Attendance management. the sensor technology antenna can be installed in teaching building, it can realize distance induction, it also used in learners' class attendance, as learners, carrying distance RFID Card, passed the entrance of teaching building, they are sensed by recognition system, it can recognize and record learners' class attendance precisely, to make visualization management by the way of network.

4) Positioning management. It can realize the orientation of learners, the guidance of campus lab, the cicerone of campus, and their method is the same, no longer described.

\subsection{Sensor Technology Used in Conference Organizing of Intelligent Learning Environment}

Intelligent conference room to install the digital facilities, such as the chair with sensors and the white board with the function of memory, participants can start projector through the use of PDA (personal digital assistant) in every corner of the room. The entrance of intelligent conference room can identify device through sensor technology, when attendants with sensor technology card (electronic card) into the venue, the system will be automatic identification through the reader of sensor technology, and it can display identity in the display screen, seat guide ,it also can set the guests welcome message, welcome speech through the network system.

\subsection{Sensor Technology Used in Establishment of Intelligent Library}

In intelligent learning environment, the reader with mobile client (laptop PDA, etc.) into the universal environment, through the distributed service sensor, it will be automatic context awareness, identifying the environment of user or service request of user, and then the service sensor sent a service request to proxy server with corresponding function, and proxy server will service request for forwarding to intelligent library, and asking intelligent library provide corresponding service results according to service request, and service results will be back to the sensor through the proxy server, and finally service results will be feedback to the mobile client of user by sensor.

\subsection{Sensor Technology Used in Information Monitoring of Intelligent Learning Environment}

The classroom by decorated sensor node can monitor the 
temperature and light of every corner of the classroom, and according to the predetermined threshold to adjust the brightness of classroom's floodlight and air-condition temperature automatically, according to the outdoors light intensity to adjust curtain height, etc., they can provide a comfortable study environment to learners, and promote learners to learn it well. In addition, the light, air conditioning, computer equipment of classroom and laboratory can control the power switch according to personnel entrances automatically. The supply load of the learners' dormitory can realize real-time remote monitoring through campus network, it quickly found that the great change of electricity load, prevent fire, electric shock, etc. [9]

\subsection{Sensor Technology Used in Information Collection of Intelligent Learning Environment}

The method of collecting information of intelligent learning environment includes automation and artificial: automation is to collect data way from the objective environment through the sensor equipment, such as the physical environment information, audio and video monitoring information and various sensor information related to the learners at the event site. [10] The method of collecting information of automation information includes data crawling, the sensor technology and the design of human-computer interaction. Data crawling is often used in acquisition and analysis of related data in massive dataset. The feasibility of method of data acquisition depends on a direct or indirect relation between data collected and learning activities, and the data scale. For example, in order to analysis learning process of learners in online learning situation, collecting learners keywords retrieval records from study system, and analysis of keywords trend of learners through the text mining algorithm.

\subsection{Sensor Technology Used in Equipment Sharing of Intelligent Learning Environment}

The wireless sensor network and sensor technology equipment can be used for real-time monitoring, bearing the RFID label to the various types of equipment or sensor installation, distribution of personal management to carry out unified management and scheduling. When the equipment idle, wireless sensor first time can inform management center, remind administrator, see the position of the equipment from the screen, and let the requester use; When the equipment is in use state, the sensor technology read equipment information, and match carriers identity information (prior to equipment owner distribution identity information sensor technology, combined with the smart card), matching information show that equipment is in use state, and equipment owner receive message through the SMS platform, providing visual management for manager.

\section{Conclusions}

Along with the development of the sensor technology and the promoting of "intelligent city", intelligent learning environment construction will become the main development direction of future information, intelligent learning environment construction, as a new things, many schools will feel lost in planning and watching, because there is no successful case can reference, there is no authoritative saying to the understanding of "intelligent". This paper has exploration and research to the sensor technology in the intelligent of learning environment management, organization, the learners library construction, information collection, information monitoring and equipment sharing application of, for intelligent learning environment construction planning for reference, according to the "intelligent the earth" and "intelligent city" idea of construction.

\section{Acknowledgements}

The paper, the Department of Yibin University pedagogy first discipline funded

\section{REFERENCES}

[1] X. Zhang and J. Zheng, "From the Perspective of a Patent, the Situation and Trend of Innovation of Global Nanometer Sensor Technology," Science and Technology Management Research, Vol. 17, 2011, pp. 30-31.

[2] J. H. Liu, “Intelligent Sensor System,” Xi'an Electronic and Science University Press, 2010, Vol. 5.

[3] W. D. Chen, X. D. Ye and J. P. Zhang, "Interaction Form and Characteristics Study of Future Classroom," E-education Research, Vol. 8, 2011, pp. 96-98.

[4] Y. F. Li and L. C. Li, "The Design and Construction of Online Learning Mode Based on Emotion Calculation and Web3D Technology," Chinese Audio-Visual education, Vol. 8, 2011, pp. 131-132.

[5] R. H. Huang, J. F. Yang and Y. B. Hu, "From the Digital Learning Environment to Intelligent Learning Environment-------the Change and Trend of Learning Environment," Open Education Research, Vol. 01, 2012, pp. 76-79.

[6] J. Zhang, Y. N. Wang and J. Zhang, “The Design of Intelligent Learning Environment Based on Pervasive Computing,” Modern Distance Education, Vol. 5, 2009, pp. 9-11.

[7] J. L. Jia and Y. H. Yang, "The Study of Mobile Learning Based on Intelligent Phone," Software Guide (education technology),” Vol. 01, 2009, pp. 80-81.

[8] Y. B. Zhang, "Application of RFID Technology to the 
Intelligent Campus,” Software Guide, Vol. 5, 2011, pp. 132-134.

[9] G. Hui, "Discussion on Application of EPC System Network in the Teaching and Management of University," Software Guide, Vol. 11, 2011, pp. 113-115.
[10] Y. H. Zhang, "Study Situations Identification of Intelligent Learning Environment -----Let the Learning Environment Service Learners Effectively,” Open Education Research, Vol. 01, 2012, pp. 86-88. 